\section{Commentary: Renal replacement therapy in cardiac surgery patients: An urgent need for consensus}

\author{
Juan Bustamante-Munguira, MD, PhD, MSc, MPH, ${ }^{a}$ \\ and Armando Coca, $\mathrm{MD}, \mathrm{PhD}^{\mathrm{b}}$
}

Acute kidney injury (AKI) is a potentially reversible clinical syndrome associated with multiple etiologies that lead to kidney function impairment of varying intensity, with associated increased morbidity and mortality. ${ }^{1}$ AKI is especially common in cardiac surgery patients. Several mechanisms can induce renal dysfunction, including exogenous and endogenous toxins, inflammation, hemodynamic and oxidative stress, or ischemia-reperfusion injury. ${ }^{2}$

Management of AKI is based on 3 key points: (1) treatment of the underlying causes of renal injury, if they have been identified and if such treatment is available; (2) avoiding further insult; and (3) offering supportive care. Although numerous pharmacologic approaches have been developed in the effort to find an effective therapy for AKI, none has been effectively translated into the real-world clinical setting. ${ }^{3}$

Renal replacement therapy (RRT) has become a cornerstone of severe AKI management, especially among the critically ill. RRT can correct AKI-related fluid, electrolyte, and acid-base disturbances. However, this therapy is not without risks, and there is no consensus regarding the most appropriate time to start its use or regarding other aspects, such as dialysis dosage or the effects of RRT on renal recovery. In this issue of JTVCS Open, Merritt-Genore and

From the Departments of ${ }^{\mathrm{a} C}$ Cardiac Surgery and ${ }^{\mathrm{b}}$ Nephrology, Hospital Clínico Universitario de Valladolid, Valladolid, Spain.

Disclosures: The authors reported no conflicts of interest.

The Journal policy requires editors and reviewers to disclose conflicts of interest and to decline handling or reviewing manuscripts for which they may have a conflict of interest. The editors and reviewers of this article have no conflicts of interest.

Received for publication March 27, 2021; revisions received March 27, 2021; accepted for publication March 29, 2021; available ahead of print April 23, 2021.

Address for reprints: Juan Bustamante-Munguira, MD, PhD, MSc, MPH, Head of Cardiac Surgery Department, Hospital Clínico Universitario de Valladolid, Valladolid, Spain (E-mail: jbustamantemunguira@gmail.com).

JTCVS Open 2021;6:200-1

2666-2736

Copyright (C) 2021 The Author(s). Published by Elsevier Inc. on behalf of The American Association for Thoracic Surgery. This is an open access article under the CC BY-NC-ND license (http://creativecommons.org/licenses/by-nc-nd/4.0/).

https://doi.org/10.1016/j.xjon.2021.03.020

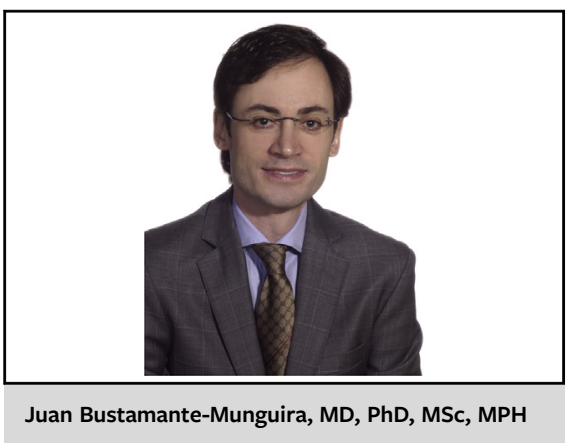

CENTRAL MESSAGE

In cardiac surgery patients, it is necessary to reach consensus regarding the diagnosis of acute kidney injury (AKI), criteria for RRT initiation of renal replacement therapy, and clinically relevant objectives in patients who develop AKI.

colleagues ${ }^{4}$ concisely review the currently available evidence associated with the timing of RRT initiation in cardiac surgery patients and its outcomes, highlighting many gaps in knowledge regarding the most appropriate way to apply this therapy.

In a minority of cases, initiation of RRT is due to a handful of life-threatening complications, such as pulmonary edema, hyperkalemia, or metabolic acidosis, that are refractory to pharmacologic management or uremic complications, such as encephalopathy or pericarditis. ${ }^{5}$ In all other cases, the appropriate timing of RRT initiation remains unclear. Previous studies offer contradictory results. Several recently published meta-analyses failed to detect a survival benefit associated with early initiation of RRT in different clinical contexts, such as patients with sepsis and patients requiring intensive care or cardiac surgery.,

However, clinical trials in this setting are marred by a lack of consensus in several key aspects, such as the definition applied for AKI diagnosis and severity or RRT modality (continuous vs intermittent), type of dialysis membrane, and dosage. Patients who require intensive care and RRT can differ significantly and might require a substantially different approach. In this context, one size may not fit all.

It is worth noting that as a therapy, RRT is not without potential adverse effects, such as hypotension and catheterrelated infections; early initiation of RRT could increase 
the risk of such complications. ${ }^{7,8}$ Moreover, the combined effect of timing, modality, dialysis membrane, and circuit anticoagulation on patient and renal outcomes post-RRT have not been adequately addressed in clinical studies. ${ }^{9}$

A joint effort is needed to reach a consensus regarding AKI diagnosis, criteria for RRT initiation, and clinically relevant objectives in patients who require RRT. ${ }^{10}$ Future randomized clinical trials should aim to describe not only the effect of timing on patient prognosis, but also its relationship with other aspects of the therapy and its impact on short- and long-term renal outcomes.

\section{References}

1. Hoste EAJ, Kellum JA, Selby NM, Zarbock A, Palevsky PM, Bagshaw SM, et al. Global epidemiology and outcomes of acute kidney injury. Nat Rev Nephrol. 2018; 14:607-25.

2. Coca A, Aller C, Reinaldo Sánchez J, Valencia AL, Bustamante-Munguira E, Bustamante-Munguira J. Role of the furosemide stress test in renal injury prognosis. Int J Mol Sci. 2020;21:3086.
3. Chen H, Busse LW. Novel therapies for acute kidney injury. Kidney Int Rep. 2017;2:785-99.

4. Merritt-Genore HM, Sarber K, Thompson S. Accelerated versus delayed initiation renal-replacement strategies following cardiac surgery. J Thorac Cardiovasc Surg Open. 2021;162:193-7.

5. Palevsky PM. Renal replacement therapy in AKI. Adv Chronic Kidney Dis. 2013; 20:76-84.

6. Gaudry S, Hajage D, Benichou N, Chaïbi K, Barbar S, Zarbock A, et al. Delayed versus early initiation of renal replacement therapy for severe acute kidney injury: a systematic review and individual patient data meta-analysis of randomised clinical trials. Lancet. 2020;395:1506-15.

7. Li X, Liu C, Mao Z, Li Q, Zhou F. Timing of renal replacement therapy initiation for acute kidney injury in critically ill patients: a systematic review of randomized clinical trials with meta-analysis and trial sequential analysis. Crit Care. 2021;25:15.

8. Fayad AII, Buamscha DG, Ciapponi A. Timing of renal replacement therapy initiation for acute kidney injury. Cochrane Database Syst Rev. 2018;12: CD010612.

9. Schneider AG, Bagshaw SM. Effects of renal replacement therapy on renal recovery after acute kidney injury. Nephron Clin Pract. 2014;127:35-41.

10. Zhang L, Chen D, Tang X, Li P, Zhang Y, Tao Y. Timing of initiation of renal replacement therapy in acute kidney injury: an updated meta-analysis of randomized controlled trials. Ren Fail. 2020;42:77-88. 